\section{AMA issues guidelines on end of life care}

Fred Charatan, Florida

The American Medical Association's council on ethical and judicial affairs recommends a process based approach to deal with disputes about medical futility in end of life care, according to an article in the latest issue of JAMA (the journal of the American Medical Association 1999;281:937-41).

The process aims to tackle the problem of how and when doctors may discontinue treatment in cases where a patient is terminally ill.

Precedence is given to the wishes of the patient, or to his or her proxy in cases where the patient is unable to make any decisions. The council recommends four steps to try to reach a resolution to a dispute and states that, if agreement is reached at any point along the way, the parties need not continue to the next step.

First, it recommends that parties try to reach an understanding as early as possible, before the patient reaches the terminal stage, about what care would be considered futile and what care falls within acceptable limits for the doctor, family, and, possibly, the institution.

Secondly, it recommends joint decision making between patient and doctor using outcome data (showing the success rate of certain treatments) to determine the value to the patient of his or her treatment goals.

Thirdly, it suggests the participation of consultants to facilitate discussions that would help the parties reach a course of action.

Lastly, it recommends the participation of an ethics committee, structured to give the patient or the patient's proxy his or her full voice, "whether by having a lay representative on the committee, by having a full hearing from the patient or proxy or advocate/representative, by ensuring that the patient or proxy can call for ethics committee involvement, or by all of the above."

If agreement still cannot be reached, the association recommends two further steps aimed at securing the desired care for the patient. The doctor and patient should consider transferring care to another doctor in the same institution, or transferring the patient to another institution

The council recommends that healthcare institutions, whether large or small, adopt a policy on medical futility, and that policies on medical futility follow a fair process approach such as that presented above.

Dr Arthur Caplan, director of the Center for Bioethics at the University of Pennsylvania School of Medicine, said that it was praiseworthy of the association to address the difficult problem of medical futility.

He pointed out that there were two factors which would undercut even the best of processes. There was a growing distrust on the part of patients and their families arising from managed care with its emphasis on cost control; and for most treatment outcomes good data simply do not exist.

\section{Audit Commission recommends home nursing shake up}

Pat Anderson, London

The NHS's home nursing service needs radical change in order to meet rising demand, according to the Audit Commission.

The commission, which is responsible for overseeing the use of public money in England and Wales, says district nursing services are overstretched and need modernisation, in a report published last week.

Demand for professional nursing care at home is increasing because the population of elderly people in the United Kingdom is growing, hospitals are discharging patients earlier, and more patients with serious or terminal illness are choosing to be nursed at home. The commission has found that district nursing services may not be available for those who need them.

It said that a third of trusts have no night nursing services so people may be admitted unnecessarily to hospitals or nursing homes, and few trusts seem to have considered how district nursing services fit in with other local services so patients may receive either duplicate services or none at all.

The report shows that referrals to district nurses by GPs and hospitals vary, and referral criteria are often unclear, wasting hours services. both nurses' and patients' time. At the same time, the number and skills of staff on a district nursing team may bear little relation to the numbers and needs of the patients that they care for.

The commission recommends that trusts define the objectives and roles of the service, try to produce clear referral criteria, and match numbers and skills of nurses to patients' needs. They should also ensure that the skills and knowledge of district nurses are up to date, and they should review out of

Primary care groups, which

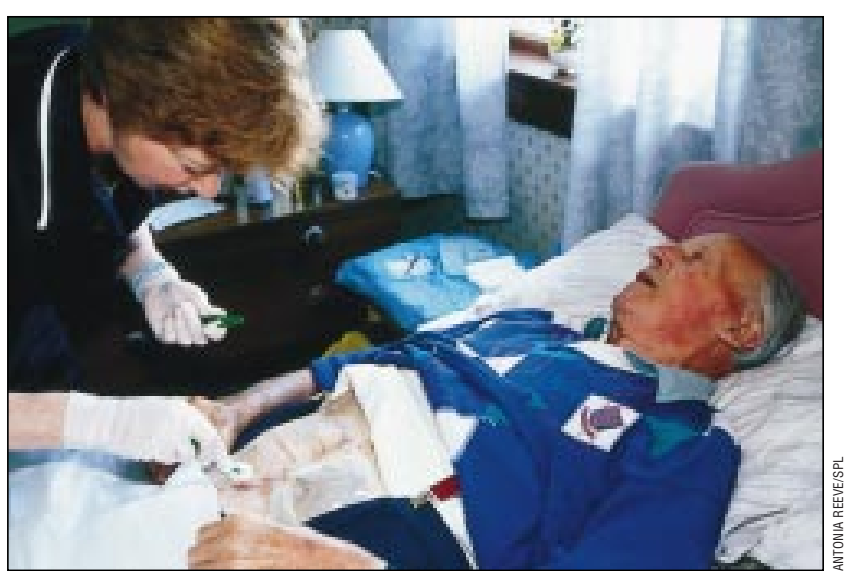

Demand for in home nursing care is increasing

come into being on 1 April, will provide a way for nurses to influence the development of district nursing by giving them a say in the use of money from local health services. The commission's report says that district nurses need to find a place as equals on these groups.

Heather Ballard, professional officer for the Community and District Nursing Association commented: "This report has confirmed the challenges we are facing, including a shameful inequality in services available in different areas."

First Assessment: A Review of District Nursing Services in England and Wales is available from Audit Commission Publications, Bookpoint, 39 Milton Park, Abingdon, Oxon OX14 4TD (tel: 0800 502030), price $£ 20$.

\section{Doctors may lose sole authority to prescribe}

John Warden, parliamentary correspondent, BMJ

Legal authority to prescribe medicines in the United Kingdom could be extended to professional groups other than doctors or dentists under proposals circulated by the health departments for consultation.

New categories of prescribers might include specialist diabetes or asthma nurses, and preregistration house officers.

Some 25 recommendations for change are covered by the report of a team headed by $\mathrm{Dr}$ June Crown, director of the South East Institute of Public Health.

Two types of prescriberindependent and dependentwould be recognised. The independent category would cover those who are currently legally authorised prescribers with some other health professionals to be added. Dependent prescribers would be those responsible for the continuing care of patients; they would be allowed to issue repeat prescriptions and adjust dosages.

Copies of the report are available from NHS response line (tel: 0541555 455). 